\title{
Barrel-to-barrel variation of phenolic and mineral composition of red wine
}

\author{
A. Pilet ${ }^{1, \text { a }}$, R.B. de Sousa ${ }^{1}$, J.M. Ricardo-da-Silva ${ }^{1}$, and S. Catarino ${ }^{1,2,3, b}$ \\ ${ }^{1}$ LEAF, Instituto Superior de Agronomia, Universidade de Lisboa, Tapada da Ajuda, 1349-017 Lisboa, Portugal \\ ${ }^{2}$ Instituto Nacional de Investigação Agrária e Veterinária, 2565-191 Dois Portos, Portugal \\ ${ }^{3}$ CEFEMA, Instituto Superior Técnico, Universidade de Lisboa, Av. Rovisco Pais, 1, 1049-001 Lisboa, Portugal
}

\begin{abstract}
The aim of the present work was to evaluate the effect of barrel-to-barrel variability on chemical characteristics of red wine. An experimental trial was carried out involving two red wines from the Portuguese DO Dão and independent replicates of French oak barrels (Quercus sessiliflora Salisb.) from three different cooperages. After six months of aging, comprehensive chemical characterization of the wines took place: general physical-chemical analysis by FTIR, phenolic composition and chromatic characteristics, major mineral elements $(\mathrm{K}, \mathrm{Mg}, \mathrm{Ca}, \mathrm{Na}$, and $\mathrm{Fe}$ ) by flame atomic absorption spectrometry (FAAS), minor and trace elements (Li, Be, Ti, Mn, Co, Ni, Cu, Zn, Ga, As, Rb, Sr, Y, Zr, Nb, Mo, Cd, Sn, Sb, Cs, Ba, Ce, Pr, Nd, $\mathrm{Sm}, \mathrm{Eu}, \mathrm{Gd}, \mathrm{Tb}, \mathrm{Dy}, \mathrm{Ho}, \mathrm{Er}, \mathrm{Tm}, \mathrm{Yb}, \mathrm{Lu}, \mathrm{W}, \mathrm{Tl}, \mathrm{Pb}$, and $\mathrm{U}$ ) by inductively coupled plasma mass spectrometry (ICP-MS). In respect to barrel effect, significant differences between replicates were observed for phenolic composition, especially polymerized pigments, flavonoids and color intensity. Regarding major, minor and trace elements, no significant differences were observed between barrel replicates with exception of iron and copper.
\end{abstract}

\section{Introduction}

Wine aging in oak barrels has been used worldwide for over 2000 years [1], at first for storage purposes, more recently to enhance the stability and sensory characteristics of wine.

This enological practice is still widely used nowadays for red wines, though it is time consuming and expensive. Because of the physical and chemical characteristics of the wood, many reactions and transfers to the wine take place in a barrel during time [2].

The transfer of compounds from the wood to the wine and the oxygen permeation through the barrel have a strong effect on the phenolic composition and sensory characteristics of the final product. Many studies showed that those phenomena are highly influenced by several parameters [3]: the wood species [4] and geographic origin [5], the barrel volume [6], the barrel processing [7], especially the drying temperature [8] and time of toasting [9], the barrel age [10] and the time of aging [11]. According to winemaker's empirical knowledge, a tangible variability also exists between the characteristics of wines resulting from aging in similar barrels coming from the same cooperage. In spite of this, only scarce information is available on barrel-to-barrel variation and its effect on wine characteristics. Doussot et al. [12] studied the interindividual variability of six oak extractible

\footnotetext{
${ }^{a}$ Master student from Chimie ParisTech, PSL Research University, 11 rue Pierre et Marie Curie, 75005 Paris, France

${ }^{\mathrm{b}}$ Corresponding author: Sofia Catarino, LEAF, Instituto Superior de Agronomia, Universidade de Lisboa, Tapada da Ajuda, 1349-017 Lisboa, Portugal

e-mail: sofiacatarino@isa.ulisboa.pt
}

compounds by measuring it in a high number of trees from two botanical species and from six different forests. Towey et al. [13] quantified seven volatile oak extractives in barrel-fermented Chardonnay wines. Wines from four different barrel types, using samples from ten similar barrels for each type were analyzed for this study and a variance of individual compounds ranging from $15 \%$ to $40 \%$ was reported.

It is known that the mineral composition of wine depends on several parameters such as vineyard soil, grape variety and rootstock, environmental conditions, viticultural technology and enological practices [14]. In a previous study of the authors, the evolution of the elemental composition of red wine aged with oak staves was investigated [15]. However, concerning wine aging using barrels, research is usually focused on the compounds more directly linked to the organoleptic properties of wines, mostly phenols and volatile compounds.

The present study aims to evaluate the effect of barrelto-barrel variability through a comprehensive analytical characterization of red wines aged in barrels: general physical-chemical characterization, extended phenolic composition, and mineral profile were investigated.

\section{Material and methods}

\subsection{Wines and oak wood barrels}

Two red wines of Touriga Nacional grape variety (Vitis vinifera L.), 2016 vintage, from the Portuguese DO Dão were produced at industrial scale.

The initial physical-chemical characteristics of the wines after malolactic fermentation were as 


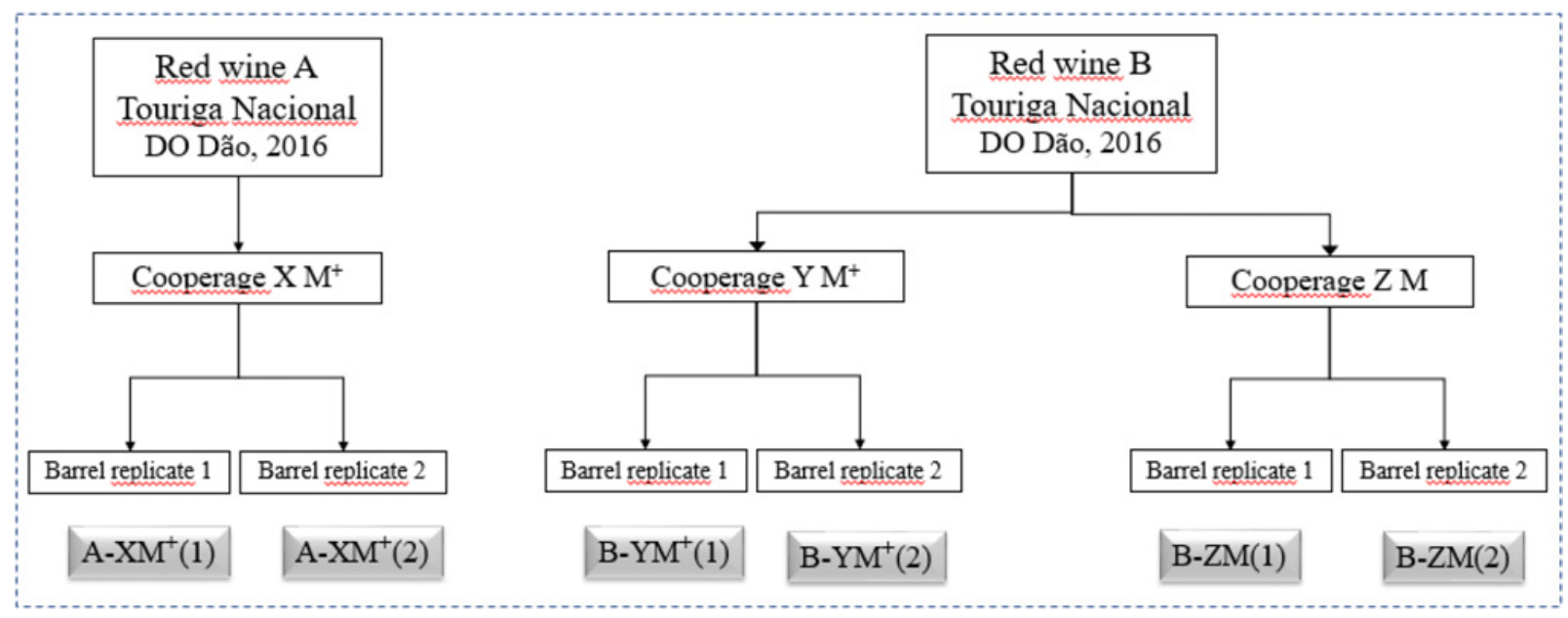

Figure 1. Experimental design of the trial involving wines aged in barrels from 3 cooperages and 2 toast levels with samples codes.

follows: alcoholic strength, $13.1 \%$ vol; total dry matter, $27.7 \mathrm{~g} / \mathrm{l}$; total acidity, $5.54 \mathrm{~g} / \mathrm{l}$ (expressed in tartaric acid); volatile acidity, $0.72 \mathrm{~g} / \mathrm{l}$ (expressed in acetic acid); total sulfur dioxide, $44 \mathrm{mg} / 1$; $\mathrm{pH} 3.65$; total phenol index, 60.6 u.a. for Wine A and alcoholic strength, $13.2 \%$ vol; dry extract, $28.8 \mathrm{~g} / 1$; total acidity, $4.33 \mathrm{~g} / 1$ (expressed in tartaric acid); volatile acidity, $0.54 \mathrm{~g} / \mathrm{l}$ (expressed in acetic acid); total sulfur dioxide, $52 \mathrm{mg} / \mathrm{l}$; $\mathrm{pH}$ 3.66; total phenol index, 71.2 u.a. for Wine B.

The wines were aged in 2251 new barrels of French oak, botanical specie Quercus sessiliflora Salisb. Barrels from three different cooperages (X, Y and Z) and with two different toast levels, medium toasting $(\mathrm{M})$ and medium plus toasting $\left(\mathrm{M}^{+}\right)$were used in the experiment.

\subsection{Experimental design}

Six months after the vinification, the wines were put in barrels. Wine A was aged in medium toast and medium plus toast barrels from cooperage $\mathrm{X}$ (respectively codified as $\mathrm{A}-\mathrm{XM}$ and $\mathrm{A}-\mathrm{XM}^{+}$), while Wine $\mathrm{B}$ was aged in medium toast and medium plus toast barrels from cooperage $\mathrm{Y}$ (respectively codified as $\mathrm{B}-\mathrm{YM}$ and $\mathrm{B}-\mathrm{YM}^{+}$) and in medium toast barrels from cooperage $\mathrm{Z}$ (codified as $\mathrm{B}-\mathrm{ZM}$ ). Two independent barrel replicates (referred to as respectively 1 and 2 after the barrel type code) were available for three of the five barrel types as shown Fig. 1. The wines were sampled after 4 months and 6 months of aging in the casks for general characterization, phenolic profile and mineral composition analyses.

\subsection{Wine general physical and chemical characterization}

The following parameters were determined by means of Fourier transfer - infrared spectrometry: density at $20^{\circ} \mathrm{C}$, alcoholic strength at $20^{\circ} \mathrm{C}$, total dry matter, reducing substances, total acidity, volatile acidity, total sulphur dioxide, $\mathrm{pH}$, ash, glycerol, sulphates and chlorides [16,17]. The analyses were carried out in duplicates.

\subsection{Color, pigments and phenolic composition}

\subsubsection{Color intensity and Tonality}

The chromatic characteristics of the wines were assessed following the spectrophotometric method described by the OIV [18]. The color intensity is given by the sum of optical densities calculated for $1 \mathrm{~cm}$ optical path and radiations of wavelengths 420,520 and $620 \mathrm{~nm}$. The tonality is expressed as the ratio of absorbance at $420 \mathrm{~nm}$ to absorbance at $520 \mathrm{~nm}$.

\subsubsection{Total anthocyanins, ionization index, colored anthocyanins, total pigments, polymerization index, polymerized pigments}

Anthocyanins equilibrium and pigments content were determined according to the spectrophotometric method established by Somers and Evans [19].

\subsubsection{Total phenols}

Total phenols were quantified following the OIV method for the Folin-Ciocalteu Index [18].

\subsubsection{Flavonoids phenols, non-flavonoids phenols}

Non-flavonoids phenols were assessed according to the method developed by Kramling and Singleton [20]. The flavonoid phenols content is determined by calculation by subtracting the value for non-flavonoids concentration to the value for total phenolics concentration obtained following the OIV official method Folin-Ciocalteu Index.

\subsubsection{Tanning power}

The tanning power gives information on the astringency of the wine. It was measured as described by De Freitas and Mateus [21].

\subsubsection{Monomeric flavanols and proanthocyanidins fractions}

The monomeric flavanols, oligomeric and polymeric proanthocyanidins were determined by applying an analytical procedure described by Sun et al. [22,23]. The sum of the three fractions obtained by this method corresponds to the total condensed tannins (proanthocyanidins).

All measurements for color, pigments and phenolic composition were performed on centrifuged wines and in triplicates. 

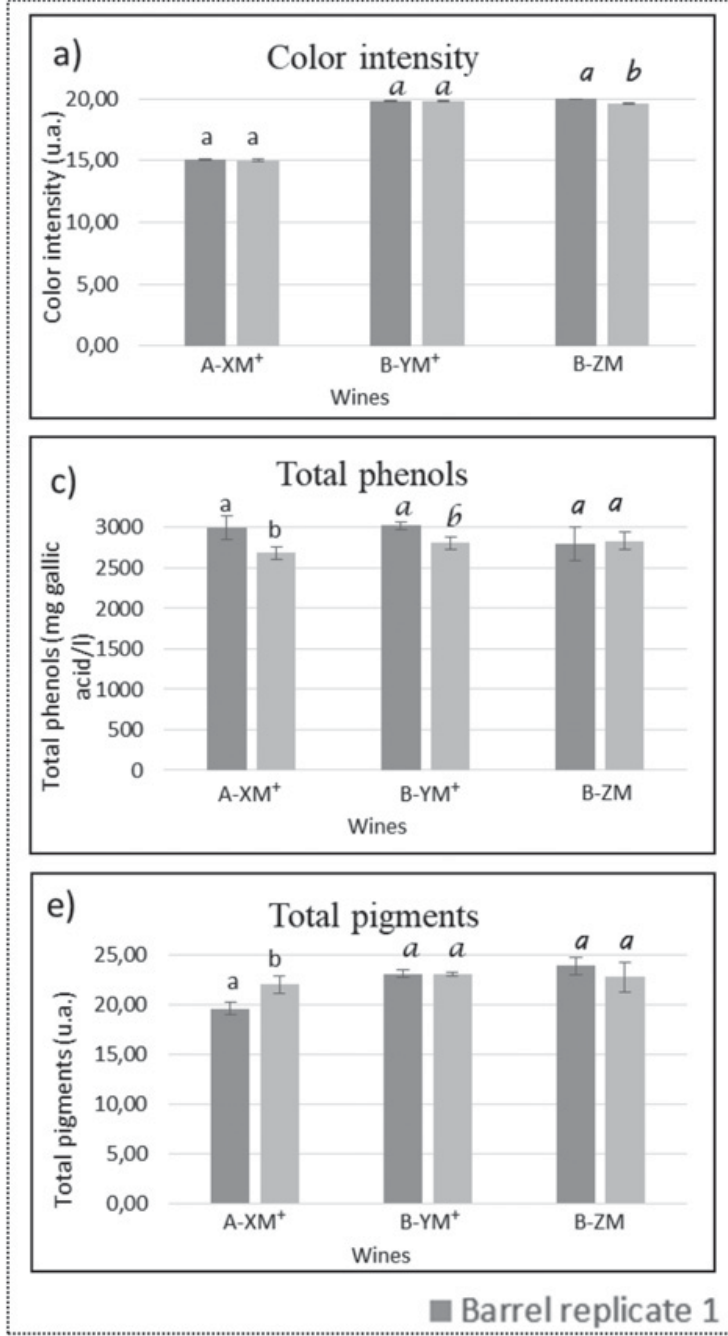
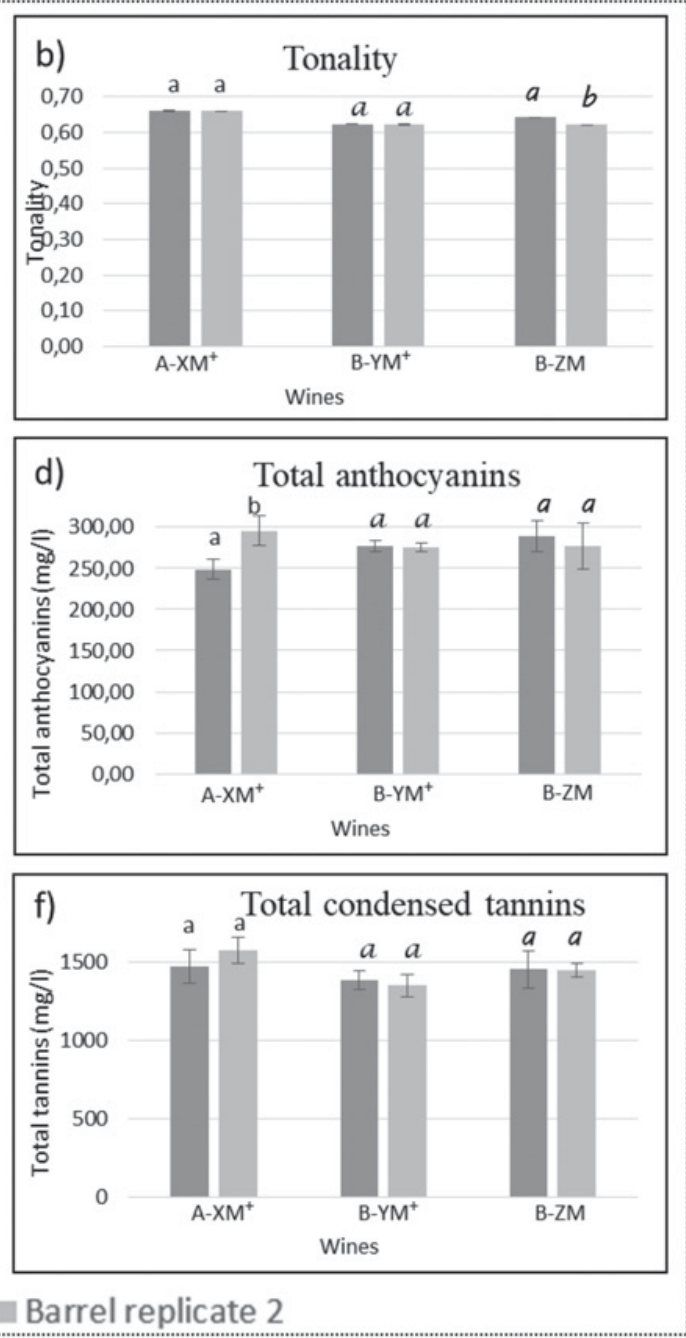

Figure 2. Effect of barrel replicates on color intensity (a), tonality (b), total phenols (c), total anthocyanins (d), total pigments (e) and total tannins (f) of red wines after 6 months of aging in different oak barrels. A-XM ${ }^{+}$, wine A aged in medium plus toasting barrels from cooperage $\mathrm{X} ; \mathrm{B}-\mathrm{YM}^{+}$, wine $\mathrm{B}$ aged in medium plus toasting barrels from cooperage $\mathrm{Y}$; $\mathrm{B}-\mathrm{ZM}$, wine $\mathrm{B}$ aged in medium toasting barrels from cooperage $\mathrm{Z}$. Results are based on the mean value of three analytical replicates. Means marked with the same letter are not significantly different at $P$ value 0.05 .

\subsection{Mineral elements composition}

\subsubsection{Major element analysis}

Concentrations of $\mathrm{K}, \mathrm{Mg}, \mathrm{Ca}, \mathrm{Na}$ and $\mathrm{Fe}$ were determined by flame atomic absorption spectroscopy (FAAS) according to the OIV method [18].

\subsubsection{Minor and trace elements analysis}

The following elements have been analysed using a quadrupole inductively coupled plasma mass spectrometry (Q-ICP-MS) semiquantitative method as described by Catarino et al. [24]: Li, Be, Ti, Mn, Co, Ni, Cu, Zn, Ga, As, Rb, Sr, Y, Zr, Nb, Mo, Cd, Sn, Sb, Cs, Ba, Ce, Pr, Nd, $\mathrm{Eu}, \mathrm{Gd}, \mathrm{Tb}, \mathrm{Dy}, \mathrm{Ho}, \mathrm{Er}, \mathrm{Tm}, \mathrm{Yb}, \mathrm{Lu}, \mathrm{W}, \mathrm{Tl}, \mathrm{Pb}$ and $\mathrm{U}$.

\subsection{Statistical analysis}

The statistical treatment was performed in order to study the barrel-to-barrel variability. The wines aged in the cooperage $\mathrm{X} \mathrm{M}^{+}$barrels, in the cooperage $\mathrm{Y} \mathrm{M}^{+}$barrels and in the cooperage $\mathrm{Z}$ M barrels respectively were treated separately. For each barrel type, factorial ANOVAs
2 factors, individual barrel and time, and Fisher LSD tests were performed. The results for each modality (i.e. individual barrel at a determined time) were based on the average values of analytical replicates. The factorial ANOVAs and the Fisher LSD tests were performed using Statistica software program (StatSoft, Inc). The chosen significance levels $(P)$ were 0.05 and 0.01 .

\section{Results and discussion}

The results presented in this article concern the effect of barrel-to-barrel variability after 6 months of wine aging in the oak barrels. Additional results for cooperage and toasting level effects and including the 4 months sampling are being prepared for future publication.

For the discussion, for each the cooperage $\mathrm{X} \mathrm{M}^{+}$, the cooperage $\mathrm{Y} \mathrm{M}^{+}$and the cooperage $\mathrm{Z} \mathrm{M}$ barrel types, the two barrel replicates were considered as independent. However, the variability in the characteristics of oak aged wines is explained, along with the low reproducibility of the cooperage practices, directly by the inherent variability of the oak trees themselves. 
Table 1. Physical-chemical characteristics of red wines ${ }^{\mathrm{a}}$ after 6 months of aging in oak barrels, according to barrel type (cooperage and toasting level) and barrel replicate.

\begin{tabular}{|c|c|c|c|c|c|c|c|c|c|}
\hline \multirow[b]{2}{*}{ Parameter } & \multicolumn{3}{|c|}{ Red wine A Touriga Nacional } & \multicolumn{6}{|c|}{ Red wine B Touriga Nacional } \\
\hline & $\begin{array}{l}\text { Barrel } \\
\text { replicate } \\
\text { effect }\end{array}$ & $\mathrm{A}-\mathrm{XM}^{+}(1)$ & $\mathrm{A}-\mathrm{XM}^{+}(2)$ & $\begin{array}{l}\text { Barrel } \\
\text { replicate } \\
\text { effect }\end{array}$ & $\mathrm{B}-\mathrm{YM}^{+}(1)$ & $\mathrm{B}-\mathrm{YM}^{+}(2)$ & $\begin{array}{c}\text { Barrel } \\
\text { replicate } \\
\text { effect }\end{array}$ & B-ZM(1) & $\mathrm{B}-\mathrm{ZM}(2)$ \\
\hline$\overline{\text { Density (g/ml) }}$ & $\mathrm{ns}^{\mathrm{b}}$ & $0.9920(0)$ & $0.9920(0)$ & ns & $0.9921(0.0001$ & $0.9920(0)$ & ns & $0.9922(0.0001)$ & $0.9922(0.0001)$ \\
\hline $\begin{array}{l}\text { Alcoholic } \\
\text { strength (\% vol.) }\end{array}$ & ns & $13.1(0.0)$ & $13.1(0.0)$ & $\mathrm{ns}$ & $13.2(0.0)$ & $13.2(0.0)$ & ns & $13.2(0.0)$ & $13.2(0)$ \\
\hline $\begin{array}{l}\text { Total dry } \\
\text { matter }(\mathrm{g} / \mathrm{l})\end{array}$ & ns & $28.3(0.1)$ & $28.3(0)$ & ns & $29.2(0.2)$ & $29.1(0)$ & ns & $29.5(0.1)$ & $29.4(0.1)$ \\
\hline $\begin{array}{l}\text { Reducing } \\
\text { substances (g/l) }\end{array}$ & $\mathrm{ns}$ & $2.0(0.2)$ & $2.1(0.1)$ & ns & $2.2(0.1)$ & $2.2(0.1)$ & ns & $2.3(0.4)$ & $2.1(0.0)$ \\
\hline $\begin{array}{l}\text { Total acidity } \\
\text { (g of tartaric acid/l) }\end{array}$ & ns & $5.23(0.01)$ & $5.23(0.02)$ & $* *$ & $5.07(0.02) \mathrm{a}$ & $5.10(0) \mathrm{b}$ & ns & $5.12(0)$ & $5.08(0.02)$ \\
\hline $\begin{array}{l}\text { Volatile acidity } \\
\text { (g of acetic acid/l) }\end{array}$ & $*$ & $0.68(0.01) \mathrm{a}$ & $0.66(0.01) b$ & ns & $0.60(0.02)$ & $0.60(0.01)$ & $*$ & $0.57(0.01) \mathrm{a}$ & $0.61(0.01) b$ \\
\hline $\begin{array}{l}\text { Total } \\
\mathrm{SO}_{2}(\mathrm{mg} / \mathrm{l})\end{array}$ & ns & $68(0)$ & $72(4)$ & ns & $86(0)$ & $81(1)$ & ns & $81(5)$ & $85(2)$ \\
\hline $\mathrm{pH}$ & ns & $3.54(0.01)$ & $3.55(0.00)$ & ns & $3.56(0.01)$ & $3.56(0.01)$ & ns & $3.56(0.01)$ & $3.58(0.01)$ \\
\hline Ash (g/l) & ns & $3.28(0.05)$ & $3.28(0.03)$ & ns & $3.45(0)$ & $3.40(0.03)$ & ns & $3.35(0.03)$ & $3.41(0.06)$ \\
\hline Glycerol (g/l) & ns & $5.1(0.3)$ & $5.2(0.1)$ & ns & $5.9(0.4)$ & $5.8(0.0)$ & ns & $5.9(0.1)$ & $5.9(0.1)$ \\
\hline $\begin{array}{l}\text { Sulfates ( } \mathrm{mg} / \mathrm{l} \text { of } \\
\text { potassium sulfate) }\end{array}$ & ns & 799 (2) & $793(4)$ & $* *$ & 849 (9) a & $868(1) b$ & ns & $855(1)$ & $865(1)$ \\
\hline $\begin{array}{l}\text { Chloride (mg/l of } \\
\text { sodium chloride) }\end{array}$ & ns & $62(0)$ & $62(0)$ & ns & $64(0)$ & $64(0)$ & ns & $64(0)$ & $64(0)$ \\
\hline
\end{tabular}

${ }^{\mathrm{a}} \mathrm{A}-\mathrm{XM}^{+}(1)$, wine $\mathrm{A}$ aged in cooperage $\mathrm{X}$ medium plus toasting barrel replicate $1 ; \mathrm{A}-\mathrm{XM}^{+}(2)$, wine $\mathrm{A}$ aged in cooperage $\mathrm{X}$ medium plus toasting barrel replicate $2 ; \mathrm{B}_{-} \mathrm{YM}^{+}(1)$, wine $\mathrm{B}$ aged in cooperage $\mathrm{Y}$ medium plus toasting barrel replicate $1 ; \mathrm{B}^{-} \mathrm{YM}^{+}(2)$, wine $\mathrm{B}$ aged in cooperage $\mathrm{Y}$ medium plus toasting barrel replicate 2; $\mathrm{B}-\mathrm{ZM}(1)$, wine $\mathrm{B}$ aged in cooperage $\mathrm{Z}$ medium toasting barrel replicate $1 ; \mathrm{B}-\mathrm{ZM}(2)$, wine $\mathrm{B}$ aged in cooperage $\mathrm{Z}$ medium toasting barrel replicate 2. Results values correspond to the mean of two analytical replicates with corresponding standard deviation (in brackets). ${ }^{\mathrm{b}} \mathrm{ns}$ : not significant effect. Means followed by the same letter are not significantly different at $0.05 *$ or $0.01 * *$. Statistical treatment was performed independently for the 3 barrel types.

Table 2. Concentration of major mineral elements (mg/l) of red wines ${ }^{\mathrm{a}}$ after 6 months of aging in oak barrels, according to barrel type (cooperage and toasting level) and barrel replicate.

\begin{tabular}{|c|c|c|c|c|c|c|c|c|c|}
\hline \multirow[b]{2}{*}{ Element } & \multicolumn{3}{|c|}{ Red wine A Touriga Nacional } & \multicolumn{6}{|c|}{ Red wine B Touriga Nacional } \\
\hline & $\begin{array}{c}\text { Barrel } \\
\text { replicate } \\
\text { effect }\end{array}$ & $\mathrm{A}^{-} \mathrm{XM}^{+}(1)$ & $\mathrm{A}-\mathrm{XM}^{+}(2)$ & $\begin{array}{c}\text { Barrel } \\
\text { replicate } \\
\text { effect }\end{array}$ & $\mathrm{B}-\mathrm{YM}^{+}(1)$ & B-YM+ ${ }^{+}(2)$ & $\begin{array}{l}\text { Barrel } \\
\text { replicate } \\
\text { effect }\end{array}$ & B-ZM(1) & B-ZM(2) \\
\hline $\mathrm{Na}$ & $\mathrm{ns}^{\mathrm{b}}$ & $15(2)$ & $12(2)$ & $\mathrm{ns}$ & $13(4)$ & $13(10)$ & ns & $12(9)$ & $12(1)$ \\
\hline $\mathrm{Mg}$ & ns & $94(2)$ & $96(2)$ & ns & $95(1)$ & $93(1)$ & ns & $89(4)$ & $85(2)$ \\
\hline K & ns & $1293(1)$ & $1296(0)$ & $\mathrm{ns}$ & $1393(1)$ & $1400(1)$ & ns & $1400(1)$ & 1389 (1) \\
\hline $\mathrm{Ca}$ & ns & $58(1)$ & $60(2)$ & ns & $52(1)$ & $54(2)$ & ns & $55(3)$ & $53(2)$ \\
\hline $\mathrm{Fe}$ & ns & $1.15(0.01)$ & $1.14(0.01)$ & $* *$ & $1.82(0.01) \mathrm{a}$ & $1.28(0.00) \mathrm{b}$ & ns & $1.35(0.00)$ & $1.35(0.00)$ \\
\hline
\end{tabular}

${ }^{\mathrm{a}} \mathrm{A}-\mathrm{XM}^{+}(1)$, wine $\mathrm{A}$ aged in medium plus toasting barrel from cooperage $\mathrm{X}$ replicate $1 ; \mathrm{A}-\mathrm{XM}^{+}(2)$, wine $\mathrm{A}$ aged in medium plus toasting barrel from cooperage $\mathrm{X}$ replicate $2 ; \mathrm{B}-\mathrm{YM}^{+}(1)$, wine $\mathrm{B}$ aged in medium plus toasting barrel from cooperage $\mathrm{Y}$ replicate $1 ; \mathrm{B}-\mathrm{YM}^{+}(2)$, wine $\mathrm{B}$ aged in medium plus toasting barrel from cooperage $\mathrm{Y}$ replicate 2; $\mathrm{B}-\mathrm{ZM}(1)$, wine $\mathrm{B}$ aged in medium toasting barrel from cooperage $\mathrm{Z}$ replicate 1 ; $\mathrm{B}-\mathrm{ZM}(2)$, wine $\mathrm{B}$ aged in medium toasting barrel from cooperage $\mathrm{Z}$ replicate 2. ${ }^{\mathrm{b}} \mathrm{ns}$ : not significant effect; ${ }^{* *}$ significant effect $(p<0.01)$. Results expressed in $\mathrm{mg} / \mathrm{l}$ correspond to the mean of three analytical replicates with corresponding standard deviation (in brackets). Statistical treatment was performed independently for the three barrel types.

\subsection{General physical-chemical analysis}

The physical-chemical characteristics of the wines after 6 months of aging in the oak barrels are listed in Table 1. Regarding total $\mathrm{SO}_{2}$ the concentrations are higher than the initial ones, what is explained by its addition during this period of time for wine preservation. The values are in agreement with usual values found in red wine for each parameter [2]. As seen in Table 1, no significant difference between barrels was observed for most of the parameters. In what concerns volatile acidity, differences were found between the independent replicates of both the cooperage $\mathrm{X} \mathrm{M}^{+}$and the cooperage
Z M barrel types. Nevertheless, despite being statistically significant, the observed variations are not relevant under the technological point of view. Statistical significance was found on sulfates for the cooperage $\mathrm{Y} \mathrm{M}^{+}$barrels, however again this variation is not relevant from a technological point of view.

\subsection{Color, pigments and phenolic composition}

The results indicate a clear overall variation from a barrel to another in the wines parameters for color, pigments and phenolic composition. However, as seen in Fig. 2, the parameters significantly affected are not the same for 
the three studied barrel types. Color intensity, tonality, total anthocyanins, ionized anthocyanins, total pigments and polymerized pigments were found with statistical significance for only one barrel type and total phenols for two barrel types, cooperage $\mathrm{X} \mathrm{M}^{+}$and cooperage $\mathrm{Z} \mathrm{M}^{+}$. Flavonoid content of the wines present a significant difference between similar barrels $(P<0.01)$ for all of the three barrel types. For total tannins, no significant difference was observed for none of the wines, even though a significant barrel effect is found regarding the fraction of monomeric flavanols for the cooperage $\mathrm{X} \mathrm{M}^{+}$barrels (data not shown).

In respect to chromatic characteristics and phenolic composition, the barrel-to-barrel variability of the wine can be easily explained by the variability of the barrels themselves. Many parameters of the phenolic composition of wines aged in oak casks are the result, along with the oxygenation phenomena, of the interaction between the phenolic compounds of the wine and those of the wood that are extracted into the wine with time. In fact, Towey et al. [13] and Doussot et al. [12] already reported important variation of oak extractive between individual barrel from the same wood species, the same cooperage and undergoing the same technological processes.

\subsection{Mineral elements composition}

The study of trace and minor mineral elements is particularly interesting regarding legal limits, wine safety but also wine authenticity as they play an important role as discriminative tool of the wines. For most of the trace and minor element, no statistical significance of barrel-tobarrel variation was found (results not shown). However, a significant difference $(P<0.01)$ in $\mathrm{Cu}$ content was found between the wines aged in similar barrel for the three barrel types (i.e. cooperage $\mathrm{X} \mathrm{M}^{+}$, cooperage $\mathrm{Y} \mathrm{M}^{+}$and cooperage $\mathrm{Z} \mathrm{M}$ ). This variation could be explained by a different rate of precipitation as copper sulfite, which depends on the availability of sulfur anion originating from sulfur dioxide and on the oxidation-reduction potential of wine [15].

Major mineral elements are the most relevant from a technological point of view because of their effect on physical-chemical stability. Besides, $\mathrm{Na}, \mathrm{Mg}, \mathrm{K}, \mathrm{Ca}$ but also $\mathrm{Fe}$ are the main components of wood ash [25]. Having in mind that oak barrels undergo several heat treatments during their production, a transfer of those metals from the wood to the wine during aging can be expected. The concentrations of $\mathrm{Na}, \mathrm{K}, \mathrm{Ca}, \mathrm{Mg}$ and $\mathrm{Fe}$, measured by flame atomic spectrometry are presented in Table 2. For all the wines, concentration values for major elements are in the usual range of variation for wine [26]. Results for $\mathrm{Na}, \mathrm{Mg}, \mathrm{K}$ and $\mathrm{Ca}$ indicate that the concentration of those elements in the wines do not differ significantly from a barrel to another similar barrel. A significant effect of the individual barrel is observed on Fe contents in the wines aged in cooperage $\mathrm{Y} \mathrm{M}^{+}$barrels. Again, this difference seems not relevant from a technological point of view.

\section{Conclusions}

This study contributes to the understanding of barrelto-barrel variability in wine, whose management is a challenge in the industry. It also addresses a shortcoming on the scarce information available for the effect of wood aging on the multielemental composition of wine.

The authors acknowledge the company Sogrape Vinhos and the cooperages Radoux, Seguin Moreau and Sylvain for providing their facilities regarding the study development, the staff of the Laboratory of Enology of Instituto Superior de Agronomia (Diana Faria and Daniel Duarte) for technical support, and Otília Cerveira for help in Mineral Analysis Laboratory activities (Instituto Nacional de Investigação Agrária e Veterinária, Dois Portos). This research was supported by the Portuguese National Funding Agency for Science and Technology [SFRH/BPD/93535/2013; LEAF (UID/AGR/04129/2013)].

\section{References}

[1] R.S. Jackson, Wine Science: Principles and Applications, $3^{\text {rd }}$ edn. (Elsevier Academic Press, Amsterdam, 2008)

[2] P. Ribéreau-Gayon, Y. Glories, A. Maujean, D. Dubourdieu, Handbook of Enology: The Chemistry of Wine Stabilization and Treatments (John Wiley \& Sons, Ltd, Chichester, UK, 2006)

[3] S. Canas, I. Caldeira, Química Enológica - Métodos Analíticos (A.S. Curvelo-Garcia, P. Barros, Porto, 2015), p. 567

[4] J.R. Mosedale, J.L. Puech, F. Feuillat, Am. J. Enol. Vitic. 50, 503 (1999)

[5] P. Chatonnet, J.M. Ricardo-da-Silva, D. Dubourdieu, Rev. Fr. Oenol. 165, 44 (1997)

[6] L.J. Pérez-Prieto, J.M. López-Roca, A. MartínezCutillas, F. Pardo Mínguez, E. Gómez-Plaza, J. Agric. Food Chem. 50, 3272 (2002)

[7] P. Chatonnet, Influence des procédés de tonnellerie et des conditions d'élevage sur la composition et la qualité des vins élevés en fûts de chêne (Thèse doctorat, Université de Bordeaux 2, 1995)

[8] M. Vivas, Y. Glories, Rev. Fr. Oenol. 158, 28 (1996)

[9] B. Fernandez de Simon, E. Cadahia, M. del Alamo, I. Nevares, Anal. Chim. Acta. 660, 211 (2010)

[10] P. Arapitas, A. Antonopoulos, E. Stefanou, V.G. Dourtoglou, Food Chem. 86, 563 (2004)

[11] A.B. Bautista-Ortín, A.G. Lencina, M. Cano-López, F. Pardo-Mínguez, J.M. López-Roca, E. GómezPlaza, Aust. J. Grape Wine R. 14, 63 (2008)

[12] F. Doussot, P. Pardon, J. Dedier, B. de Jeso, Analusis 28, 960 (2000)

[13] J.P. Towey, A.L. Waterhouse, Am. J. Enol. Vitic. 47, 17 (1996)

[14] H. Eschnauer, Naturwissenschaften 73, 281 (1986)

[15] A.D. Kaya, R. Bruno de Sousa, A.S. Curvelo-Garcia, J.M. Ricardo-da-Silva, S. Catarino, J. Agric. Food Chem. 65, 4766 (2017)

[16] C.D. Patz, A. Blieke, R. Ristow, H. Dietrich, Anal. Chim. Acta. 513, 81 (2004)

[17] M.L. Ferreira, Química Enológica - Métodos Analíticos: Avanços Recentes No Controlo Da Qualidade de Vinhos e de Outros Produtos Vitivinícolas (Curvelo-Garcia e Barros, 2015), p. 101

[18] OIV, Compendium of International Methods of Wine and Must analysis (Paris, 2018)

[19] T.C. Somers, M.E. Evans, J. Sci. Fd Agric. 28, 279 (1977)

[20] T.E. Kramling, V.L. Singleton, Am. J. Enol. Vitic., 86 (1969) 
[21] V. de Freitas, N. Mateus, J. Agric. Food Chem. 49, 940 (2001)

[22] B. Sun, C. Leandro, J.M. Ricardo da Silva, I. Spranger, J. Agric. Food Chem. 46, 1390 (1998a)

[23] B. Sun, J.M. Ricardo-da-Silva, I. Spranger, J. Agric. Food Chem. 46, 4267 (1998b)
[24] S. Catarino, A.S. Curvelo-Garcia, R.B. Sousa, Talanta 70, 1073 (2006)

[25] D. Fengel, G. Wegener, Wood-chemistry, Ultrastructure, Reactions (de Gruyter, Berlin, Germany, 1989)

[26] S. Catarino, A.S. Curvelo-Garcia, R. Bruno, Ciênc. Téc. Vitivinic. 23, 3 (2008) 